\title{
Rheological Parameters and Transport Characteristics of Fresh Cement Tailings Backfill Slurry in an Underground Iron Mine
}

\author{
Chi Zhang $\mathbb{D}^{1,2}$ Yu-Ye Tan $\mathbb{C}^{1,},{ }^{1,2}$ Kai Zhang, ${ }^{1,2}$ Chun-Yue Zhang, ${ }^{1,2}$ and Wei-Dong Song ${ }^{1,2}$ \\ ${ }^{1}$ Civil and Resource Engineering School, University of Science and Technology Beijing, Beijing 100083, China \\ ${ }^{2}$ Key Laboratory of High-Efficient Mining and Safety of Metal Mines (Ministry of Education of China), \\ University of Science and Technology Beijing, Beijing 100083, China
}

Correspondence should be addressed to Yu-Ye Tan; tanyuye@ustb.edu.cn

Received 20 April 2021; Accepted 21 July 2021; Published 10 August 2021

Academic Editor: Jian Zhang

Copyright (c) 2021 Chi Zhang et al. This is an open access article distributed under the Creative Commons Attribution License, which permits unrestricted use, distribution, and reproduction in any medium, provided the original work is properly cited.

\begin{abstract}
Pipeline transportation is the key component of the mine filling system. In this study, fresh cement tailing backfill (CTB) slurry made by unclassified tailings from the Daye iron mine is taken as the research object, and its rheological parameters and transport characteristics are studied via laboratory test and FLUENT software. It was found that the relationship curve of the dynamic yield stress, viscosity, and solid content (SC) of CTB slurry fits the law of the H-B model when SC varies between $60 \%$ and $68 \%$. However, the relationship curve gradually changes to fit the Bingham mode when SC reaches up to $70 \%$. Numerical simulation results demonstrate that when the SC of CTB slurry exceeds $65 \%$, the static pressure at the pipeline's outlet begins to distribute symmetrically. At this point, the slurry flow state is relatively stable, and the pipeline resistance loss is positively correlated with SC and flow rate. When SC exceeds $70 \%$, resistance loss begins to increase significantly. The findings of this study can be used to identify the suitable transportation conditions of CTB slurry and provide the theoretical direction for the pipeline transportation design of filling systems in mines.
\end{abstract}

\section{Introduction}

The open stope mining method is the most widely used underground mining method because of its high production capacity, but it has led to the creation of numerous goafs, which can cause serious safety problems, such as surface subsidence, rock bursts, and strata movement $[1,2]$. The filling mining method is usually adopted to handle the mined-out areas with tailings. This kind of treatment can not only prevent surface subsidence but also effectively dispose of solid wastes and improve the resource recovery rate [3]. Moreover, as the mining depth further deepens, the backfilling body can remarkably affect the controlling ground pressure activities and prevent rock burst $[4,5]$. Therefore, in recent years, the Chinese government has vigorously advocated the use of the filling mining method in underground metal mines, as this approach is safer and more environmentally friendly, and it will likely become a trend in the future $[6,7]$. Besides, with the wide application of filling technology, the stability, reliability, and safety of filling systems have become the main problems faced by scholars.
As the mining depth further deepens, the delivery distance and the length of the transportation pipeline become increasingly longer, which complicates the transportation system, leading to many safety and stability problems (such as pipe blocking, pipe breaking, etc.) of filling systems [8]. The fresh-filling slurry transportation technology is one of the core technologies of the filling mining method. The transport characteristics of slurries are related to the design and application of the filling system $[9,10]$. Consequently, many researchers have focused on the characteristic parameters and related effects of filling pipeline transportation systems.

The pipeline transportation of a filling slurry is a kind of a solid-liquid two-phase flow [11], and its rule of flow in the pipeline is mainly affected by the solid content (SC) and flow rate of the slurry. Several researchers have recently implemented various laboratory tests to obtain flow characteristic parameters, such as yield stress and viscosity coefficient. Cao et al. [12, 13] studied the rheology and sedimentation characteristics of fresh CTB slurry with different SC and $c / t$ ratios. Yang et al. [14] found through rheological 
experiments that yield stress could increase significantly with the increase in SC when the solid-phase mass fraction of a copper tailing slurry exceeds $70 \%$. By combining experimental research with theoretical analysis, Cai et al. [15] introduced the Papanastasiou viscoplastic fluid model to characterize the variation process of viscosity and shear stress of a tailings' filling slurry. Wang et al. [16] conducted experiments on the tailings of the second mining area of a nonferrous metal mining company in Jinchuan and obtained a rheological model of the experimental slurry. Kou et al. [17] performed rheological property tests on the highconcentration filling slurry of unclassified tailings and obtained the rheological curve of paste and the optimal fitting model. Wang et al. [18] analyzed through laboratory experiments the influence of different SC on rheological properties. Wu et al. [19] constructed a mathematical model of the antisegregation property by determining its coefficient and performed the bleeding rate test experiment and slurry rheological property experiment to verify the coefficient. Because a rheometer has the advantages of saving materials, simple operation, and short experimental time, the rheological properties of CTB slurry are mainly measured by rheometer. The rheological model of slurry is obtained by fitting the relationship curve between shear rate and shear stress obtained by the rheometer. Bingham model and Herschel-Bulkley (H-B) model are the most widely used and highly recognized rheological models in the field of filling mine. However, for the practical problems to be studied, the appropriate rheological model should be selected according to the specific situation.

With the development of computer technology, the software used to simulate computational fluid dynamics has been widely adopted in the study of fluid rheological properties [20]. Among them, FLUENT is the most widely used, as it can simulate the flow of filling slurry in pipelines and subsequently obtain the distribution law of slurry pressure and flow velocity in the pipeline [21]. Chen et al. [22] used FLUENT to simulate the pipeline transportation of a filling slurry and obtained the relationship equation between slurry velocity and on-way resistance. Zhang et al. [23] simulated the pipeline transportation of a high-density filling slurry with coarse aggregates, consequently providing a theoretical basis for its application in mines. Deng et al. [24] performed a simulation experiment of the self-flow transportation of a filling slurry in an L-shaped pipeline based on FLUENT, conducted transportation numerical simulation in a long-distance pipeline, and analyzed the flow pressure, velocity, and deflection characteristics of the filling slurry with different SCs [25]. Xiao et al. [26] applied FLUENT to calculate velocity distribution and pressure loss, and the simulation result was in good agreement with the experimental results. The cost of slurry transportation experiment (L-tube or loop tube experiment) is high, and the test equipment is expensive. Computer simulation can make up for the shortcomings of traditional experimental observation methods and high costs. At the same time, for complex multiphase flow and other problems, the computer can do a good simulation analysis, which provides a powerful and fast tool for in-depth study of slurry pipeline transportation. However, in the present stage of research, there are few simulation models based on the actual filling pipeline, which cannot reflect the actual situation of mine filling, and the results are often unsatisfactory.

In this study, by taking fresh cement tailing backfill (CTB) slurry from an iron mine in Daye as the research object, the relationship between the rheological parameters and SCs of the CTB slurry were obtained through a rheological characteristic experiment. Furthermore, the pipeline transportation model was established based on the actual situation on-site, the pipeline transportation situation of the CTB slurry was simulated and analyzed using FLUENT, and the flow velocity distribution law, pressure distribution law, and influence of SC on the transportation state were studied. The findings of this study can help to determine the requirements and conditions of CTB slurry transportation, thereafter providing a theoretical basis for the design of the unclassified cemented tailing backfilling system in the iron mine in Daye, and play a vital role in ensuring the filling pipe transportation performance, improving the filling quality, and reducing the filling cost.

\section{Laboratory Test on Rheological Parameters}

\subsection{Materials}

2.1.1. Unclassified Tailings. The unclassified tailings were obtained from the underflow of a tailings thickener in an iron mine concentrator in Daye. After the tailings were retrieved, the free water was filtered with a filter cloth and then dried using a DGG-9420 dryer at $50^{\circ} \mathrm{C}$ for $18 \mathrm{~h}$. In this manner, the tailings for testing as required for the experiment could be obtained.

As shown in Table 1 and Figure 1, the grading of the unclassified tailings is not particularly uniform, there are more coarse particles and fine particles, less intermediate particles, and the average median particle size and surface volume average particle size of the tailings are smaller, which belongs to the category of fine particles. The tailings have a large separation coefficient and are suitable for underground filling [27].

The main chemical compositions of the tested tailings were determined via the $\mathrm{x}$-ray diffraction. The results are shown in Table 2; the $\mathrm{SiO}_{2}$ content was 26.30 wt. \%, while the TFe content was 20.79 wt. \%. Figure 2(a) shows the general distribution of elements by SEM; it can be seen that the general distribution of surface scan elements is rose red, purple, yellow, and black, which represent silicon, calcium, germanium, magnesium, sodium, and other elements as well as pores, indicating that the chemical elements of the whole tailings are mainly composed of these elements. Figure 2(b) shows the chemical composition of unclassified tailings by the XRD phase analyzer.

2.1.2. Water and Binder. As the composition of tap water is negligible from place to place, the effect of the varying tap water on the mechanical properties of the backfill sample can be ignored [28]. Laboratory tap water was used for the sample preparation in this experiment. In addition, Portland cement (PC) $32.5 \mathrm{R}$ was used as the binder. The physical properties of PC $32.5 \mathrm{R}$ were obtained via the constant 
TABLE 1: Physical properties of unclassified tailings.

\begin{tabular}{|c|c|c|c|c|c|c|}
\hline $\begin{array}{l}\text { Median particle } \\
\text { size } d_{50}(\mu \mathrm{m})\end{array}$ & $D(3,2)(\mu \mathrm{m})$ & Separation coefficient $S_{0}$ & Proportion $\gamma$ & Bulk density $\left(\mathrm{t} \cdot \mathrm{m}^{-3}\right)$ & Porosity $\omega(\%)$ & Surface area $\Phi\left(\mathrm{cm}^{2} \cdot \mathrm{cm}^{-3}\right)$ \\
\hline 37.925 & 14.319 & 5.595 & 3.2 & 1.47 & 57 & 6400 \\
\hline
\end{tabular}

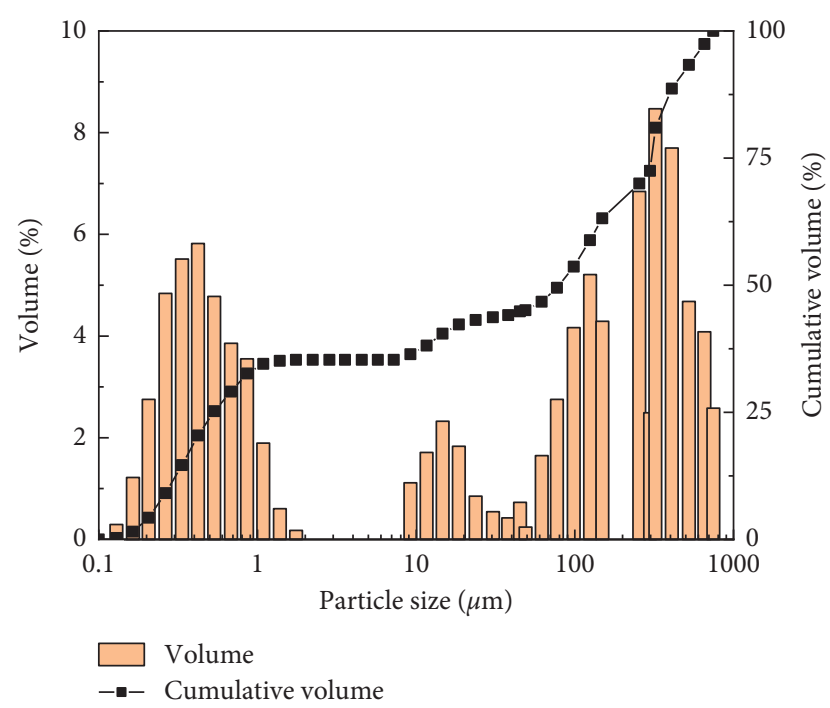

FIGURE 1: Cumulative particle size distribution curve of unclassified tailings.

volume weighing method (Table 3 ). The binder contained large quantities of $\mathrm{CaO}$ and $\mathrm{SiO}_{2}$, which are conducive to enhancing the cohesion and strength of the filling body [29].

2.2. Experimental Installations and Tests. A single factor fivelevel design was used in the experiment. The cement-totailing mass ratio was $1: 8$, and the SCs were set as $60 \%, 63 \%$, $65 \%, 68 \%$, and $70 \%$. The CTB slurry preparation was carried out in strict accordance with the experimental procedure and production standard of the filling laboratory of the University of Science and Technology Beijing. First, the cement and tailing materials were put into a basin according to a specified proportion and then mixed with hands until even mixing was achieved. Then, water was poured according to the calculated proportion, and mixing was continued using a mixer. After another round of even mixing, the fresh CTB slurry was tested using an R/S fourblade propeller rheometer. The measurement range of the rheometer is $0.01 \sim 1000 \mathrm{rpm}$, and the rotor model is VT-4020 type paddle rotor. The rheometer rotor was immersed into the fresh CTB slurry to be measured, and the rise in shear rate was controlled in the range of 0 to $120 \mathrm{~s}^{-1}$ within $120 \mathrm{~s}$. Then, the rheological parameters were monitored, and the results were outputted to the Rheo3000 computer program in real time. The change curves of apparent viscosity and shear stress are shown in Figure 3.

2.3. Results and Analysis. Fresh CTB slurry is considered to be a non-Newtonian fluid and it can be described by the Bingham model and the H-B model. Compared with the fitting results of Bingham model, $\mathrm{H}-\mathrm{B}$ model has a better fitting effect on the shear rate-shear stress curve, indicating that $\mathrm{H}-\mathrm{B}$ model is suitable for describing the shear rate-shear stress curve in this study. The H-B model can be expressed as

$$
\tau=\tau_{0}+\eta \cdot \gamma^{n}
$$

where $\tau_{0}$ is the yield stress, $\mathrm{Pa} ; \eta$ is the plastic viscosity coefficient, $\mathrm{Pa} \cdot \mathrm{S} ; \gamma$ is the shear rate, $\mathrm{s}^{-1}$; and $n$ is the flow index; when $n>1$, the material has the characteristic of shear thickening; when $n<1$, the material has the characteristic of shear-thinning; when $n=1$, it degenerates into Bingham model.

It can be seen from Figure 3(b) that the apparent viscosity decreases first and then increases with the increase of shear rate. The shear rate at the beginning of apparent viscosity increase is considered to be the critical shear rate to characterize the beginning of shear thickening. It can be seen that the critical shear rate point of the slurry is obvious, which indicates the shear thickening characteristic of the slurry.

Table 4 lists the values of shear stress with shear rate at different SCs. The Bingham model and the H-B model were used for the regression analysis, and the relationship between shear stress and shear rate was obtained. The details are shown in Figure 4 and Table 5. The comparison and analysis are as follows:

(i) With the increase in SC of the CTB slurry, the curve between shear stress and shear rate gradually transits from nonlinear to linear. When the SC reaches $70 \%$, the fitting curve tends to be linear.

(ii) When the SC of the CTB slurry is between $60 \%$ and $68 \%$, the $R^{2}$ value fitted by the $\mathrm{H}-\mathrm{B}$ model is higher than that of the Bingham model. However, with the increase in SC, the fitting degree of the Bingham model gradually increases. When the SC reaches $70 \%$, the $R^{2}$ value fitted by the Bingham model exceeds that of the H-B model. Then, the rheological state of the slurry changes from the H-B model to the Bingham model.

(iii) Bingham model is a special case of $\mathrm{H}-\mathrm{B}$ model when $n=1$. With the increase of SC of CTB slurry, the flow index $n$ of H-B model decreases and approaches 1 .

(iv) When the SC of the CTB slurry is between $60 \%$ and $68 \%$, the correlation of the H-B model is much higher than that of the Bingham model. Therefore, using the $\mathrm{H}-\mathrm{B}$ model for subsequent analysis is more reasonable for the experiment.

Table 5 shows the fitting results of the regression analysis between shear stress and shear rate of the CTB slurry. The fitting curve between SC and viscosity and dynamic yield stress is shown in Figure 5. The analysis of the trends is as follows: 


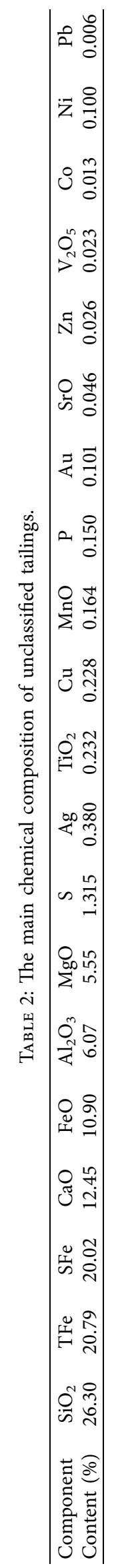



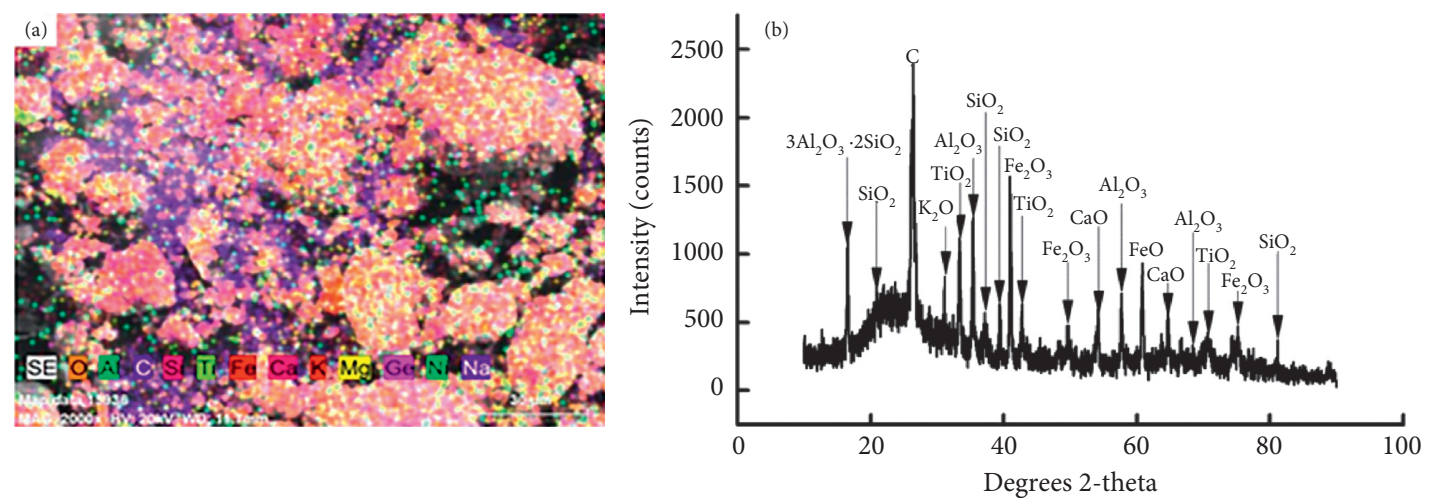

FIgure 2: (a) General distribution of elements; (b) the chemical composition of unclassified tailing.

TABLE 3: Basic physical parameters of cemented aggregate.

\begin{tabular}{lccc}
\hline Name & Proportion $\gamma$ & Bulk density $\rho\left(\mathrm{t} \bullet \mathrm{m}^{-3}\right)$ & Porosity $\omega(\%)$ \\
\hline Binder & 2.90 & 1.22 & 57.93 \\
\hline
\end{tabular}
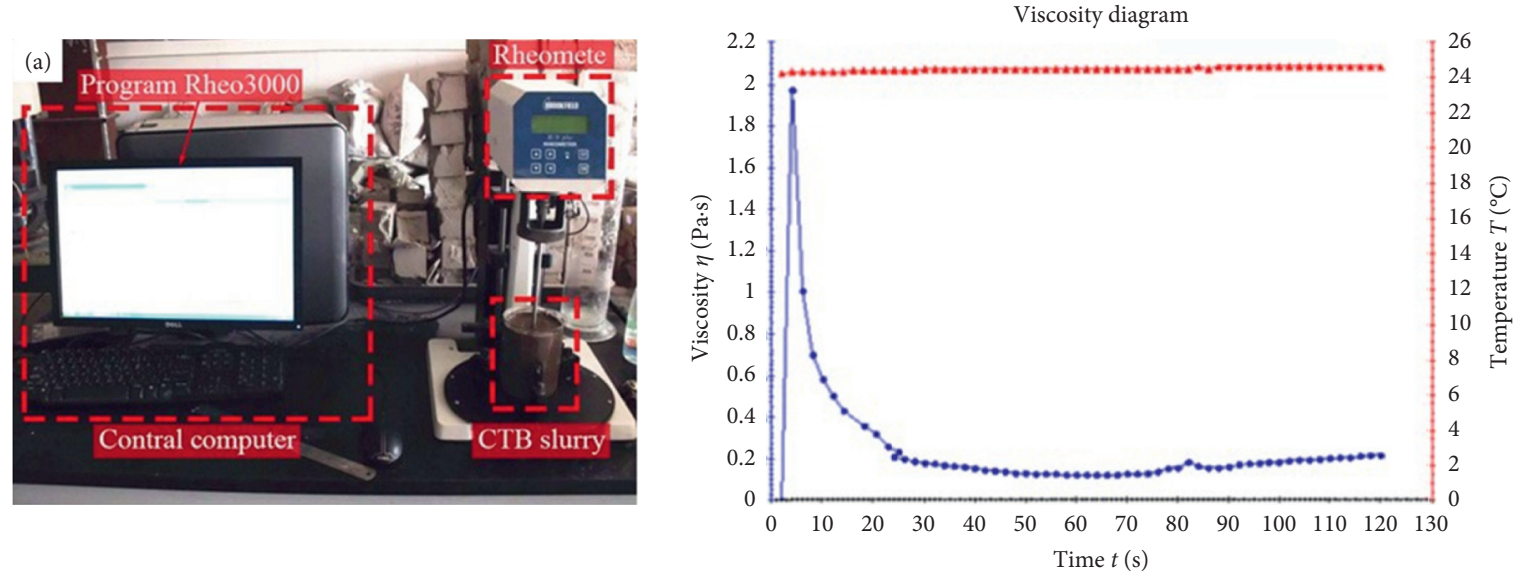

(b)

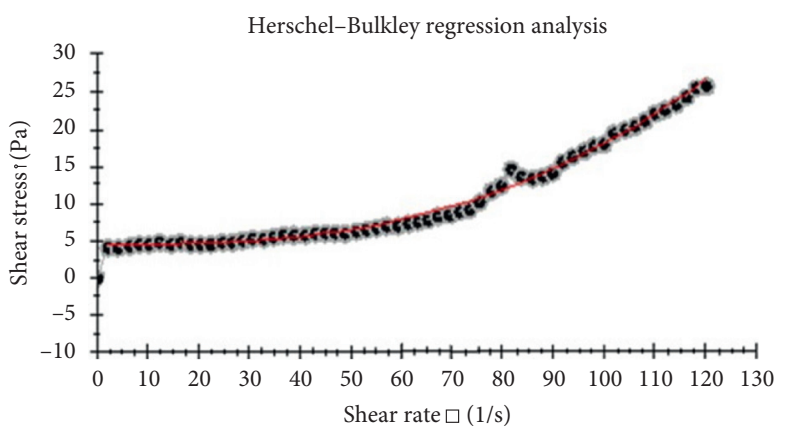

(c)

FIGURE 3: Rheometer and program Rheo3000: (a) instrument diagram; (b) apparent viscosity curve; (c) shear stress curve.

TABle 4: Shear stress at different shear rates $(\mathrm{Pa})$.

\begin{tabular}{|c|c|c|c|c|c|}
\hline \multirow{2}{*}{ Shear rate $\left(\mathrm{s}^{-1}\right)$} & \multicolumn{5}{|c|}{ SC (\%) } \\
\hline & 60 & 63 & 65 & 68 & 70 \\
\hline 10 & 4.68 & 8.62 & 18.32 & 40.96 & 101.03 \\
\hline 20 & 4.66 & 9.01 & 19.03 & 43.12 & 103.32 \\
\hline 30 & 5.24 & 9.90 & 19.90 & 44.20 & 105.51 \\
\hline 40 & 5.80 & 10.53 & 21.00 & 45.73 & 107.95 \\
\hline
\end{tabular}


TABle 4: Continued.

\begin{tabular}{|c|c|c|c|c|c|}
\hline \multirow{2}{*}{ Shear rate $\left(\mathrm{s}^{-1}\right)$} & \multicolumn{5}{|c|}{ SC (\%) } \\
\hline & 60 & 63 & 65 & 68 & 70 \\
\hline 50 & 6.25 & 10.89 & 21.55 & 47.30 & 110.19 \\
\hline 60 & 7.22 & 12.01 & 22.91 & 48.74 & 113.00 \\
\hline 70 & 8.74 & 13.47 & 23.70 & 50.56 & 116.20 \\
\hline 80 & 13.02 & 14.92 & 24.82 & 52.00 & 118.80 \\
\hline 90 & 14.72 & 16.61 & 26.00 & 53.60 & 121.01 \\
\hline 100 & 18.00 & 19.02 & 27.79 & 55.65 & 123.40 \\
\hline 110 & 21.95 & 22.93 & 30.80 & 58.11 & 126.00 \\
\hline 120 & 25.61 & 26.49 & 34.94 & 61.59 & 128.11 \\
\hline
\end{tabular}

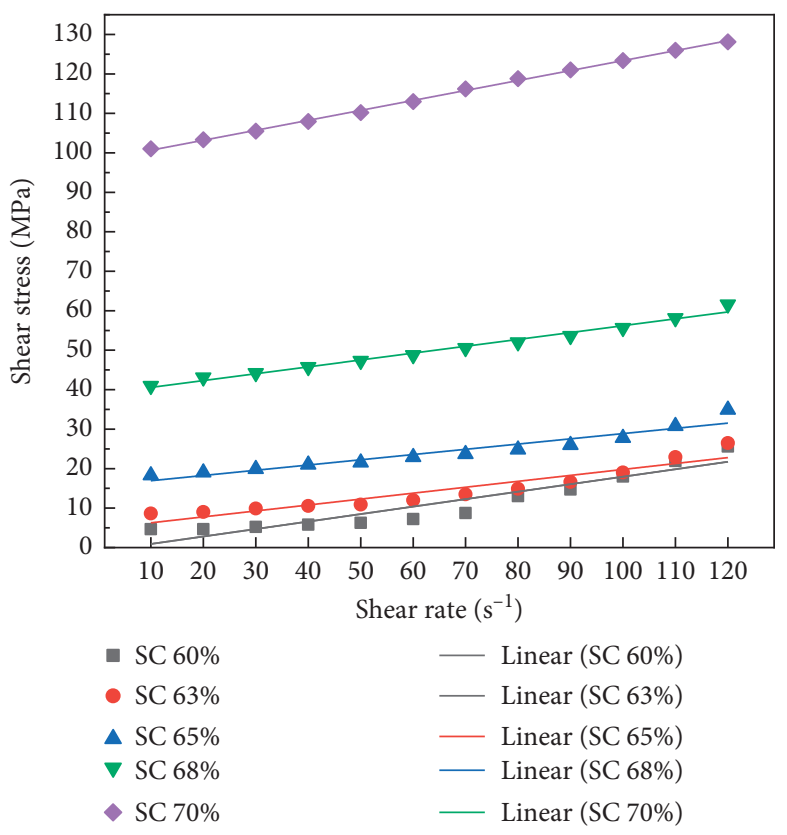

(a)

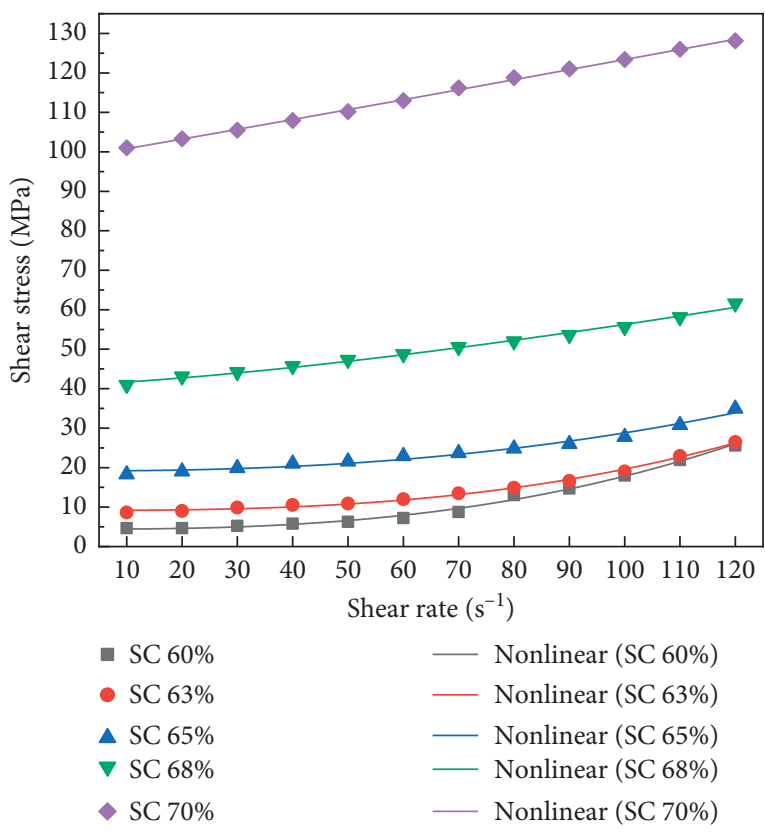

(b)

FIgURE 4: Shear stress-shear rate curves of CTB slurry with different SC: (a) Bingham model; (b) H-B model.

TABLE 5: Fitting results of CTB slurry with different SC.

\begin{tabular}{|c|c|c|c|c|c|c|}
\hline SC (\%) & Fitting model & $\tau_{0}(\mathrm{~Pa})$ & $\eta(\mathrm{Pa} \cdot \mathrm{s})$ & $n$ & Regression equation & $R^{2}$ \\
\hline 60 & $\begin{array}{l}\text { Bingham } \\
\text { H-B }\end{array}$ & $\begin{array}{c}-0.98 \\
4.41\end{array}$ & $\begin{array}{c}0.19 \\
7.85 E-5\end{array}$ & - & $\begin{array}{c}\tau=-0.98+0.19 \gamma \\
\tau=4.41+7.85 \times 10^{-5} \gamma^{2.62}\end{array}$ & $\begin{array}{l}0.88211 \\
0.99311\end{array}$ \\
\hline 63 & $\begin{array}{c}\text { Bingham } \\
\text { H-B }\end{array}$ & $\begin{array}{l}4.77 \\
9.18 \\
\end{array}$ & $\begin{array}{c}0.15 \\
4.04 E-5\end{array}$ & - & $\begin{array}{c}\tau=4.77+0.15 \gamma \\
\tau=9.18+4.04 \times 10^{-5} \gamma^{2.71}\end{array}$ & $\begin{array}{l}0.89196 \\
0.99476 \\
\end{array}$ \\
\hline 65 & $\begin{array}{l}\text { Bingham } \\
\text { H-B }\end{array}$ & $\begin{array}{l}16.60 \\
19.17\end{array}$ & $\begin{array}{c}0.13 \\
2.06 E-4\end{array}$ & - & $\begin{array}{c}\tau=15.6+0.13 \gamma \\
\tau=19.17+2.06 \times 10^{-4} \gamma^{2.34}\end{array}$ & $\begin{array}{c}0.91804 \\
0.9769\end{array}$ \\
\hline 68 & $\begin{array}{c}\text { Bingham } \\
\text { H-B }\end{array}$ & $\begin{array}{l}38.83 \\
41.07\end{array}$ & $\begin{array}{l}0.17 \\
0.03\end{array}$ & - & $\begin{array}{c}\tau=38.83+0.17 \gamma \\
\tau=41.07+0.03 \gamma^{1.37}\end{array}$ & $\begin{array}{l}0.98493 \\
0.99173 \\
\end{array}$ \\
\hline 70 & $\begin{array}{l}\text { Bingham } \\
\text { H-B }\end{array}$ & $\begin{array}{l}98.14 \\
98.47\end{array}$ & $\begin{array}{l}0.25 \\
0.22\end{array}$ & $\overline{1.03}$ & $\begin{array}{c}\tau=98.14+0.25 \gamma \\
\tau=98.47+0.22 \gamma^{1.03}\end{array}$ & $\begin{array}{c}0.9987 \\
0.99849\end{array}$ \\
\hline
\end{tabular}

(i) With the increase in SC, the slurry viscosity also increases exponentially. When the SC is between $60 \%$ and $63 \%$, the viscosity value is extremely small. When the SC is $65 \%$, the viscosity value starts to increase gradually. When the SC reaches $70 \%$, the viscosity value starts to rise sharply, and the slurry viscosity increases significantly. (ii) With the increase in SC, the dynamic yield stress of the CTB slurry increases exponentially. Furthermore, the difference in the dynamic yield stress of the adjacent SC becomes prominently large. This trend can be explained by the increase in the slurry's SC, the flocculent structure formed between solid particles and the enhanced strength between solid 


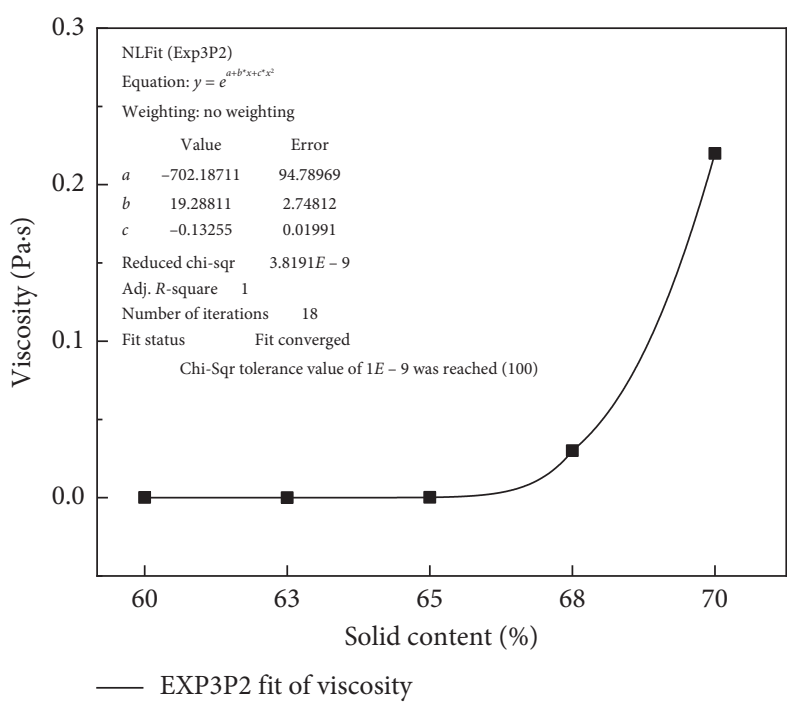

(a)

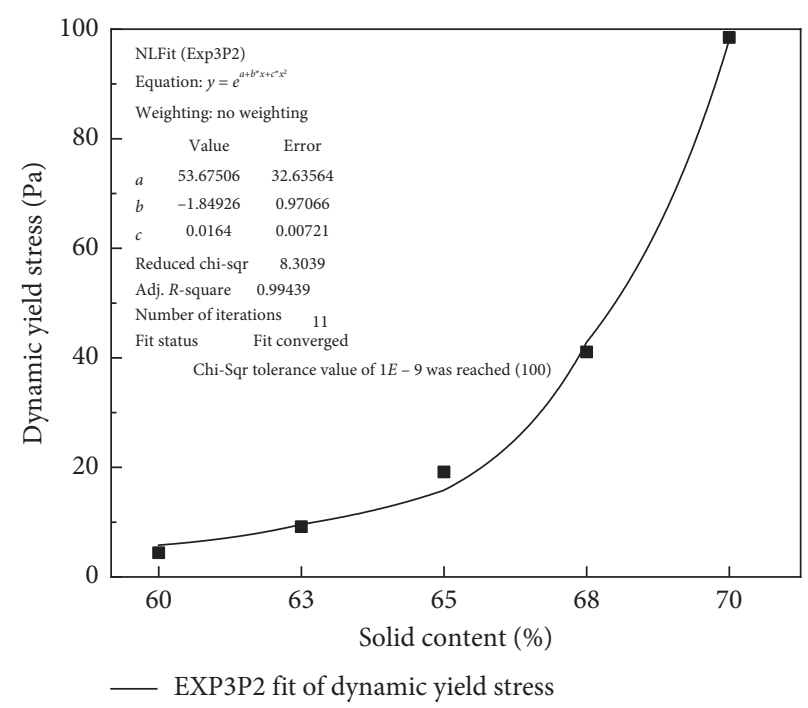

(b)

FIGURE 5: Fitting result: (a) viscosity and SC; (b) dynamic yield stress and SC.

particles and water, and the enhanced ability to resist shear deformation. However, the degree of shear failure has become severe.

\section{Numerical Simulation of Pipeline Transport Characteristics}

3.1. Simulation Scheme. Many studies have proved that the simulation results of FLUENT software accord with the actual situation and have a high reference value for industrial design. And the reliability of the simulation of slurry transport dynamic characteristics by the software is verified by natural settlement test, circular pipe test, and engineering application. In order to facilitate modeling and analysis, the basic hypothesis and prerequisite should be made before simulation [30]:

(a) The viscosity of filling slurry cannot change with time and temperature; that is, it has constant viscosity

(b) The slurry is considered to be incompressible

(c) Heat exchange is not considered in the simulation process

(d) The influence of vibration and seismic pressure waves on pipeline transportation is not considered

(e) On the initial simulation, the pipeline is full pipe flow

FLUENT uses Gambit to build calculation models and generate meshes. In consideration of the complexity of actual transportation systems and the limited ability of computer calculation, a 2D plane model was used for modeling, and the pipe network layout was simplified (Figure 6). The total length and diameter of the pipeline model were $1513 \mathrm{~m}$ and $121 \mathrm{~mm}$, respectively. Four inflection points were identified, and the inflection point was divided via local encryption. The grid spacing at the inflection point was $0.02 \mathrm{~m}$, and the grid spacing of the other parts was $0.1 \mathrm{~m}$ (Figure 6). The boundary conditions included the velocity inlet and the free outflow. The output was in the form of a Mesh file.

The Import Mesh file was used in FLUENT and a 2D double-precision solver was selected to solve the problem. The main parameter settings in the solution process are shown in Table 6 . The viscosity and density of fresh CTB slurry of different solid contents were determined through laboratory experiments rheometer test.

3.2. Analysis of the Influence of SC on Pipeline Transportation. Take the CTB slurry with a flow rate of $50 \mathrm{~m}^{3} / \mathrm{h}$ as an example. The numerical simulation results were $60 \%, 63 \%$, $65 \%, 68 \%$, and $70 \%$. Then, the velocity and pressure changes in the pipeline transportation were analyzed.

3.2.1. Analysis of Velocity Change. When the SC is between $60 \%$ and $68 \%$, the maximum velocity of the CTB slurry in the pipeline does not change much. However, when the SC reaches $70 \%$, the maximum velocity increases significantly. Furthermore, within the simulated SC range, in vertical and inclined pipes, the flow velocity of the slurry increases under the action of gravity, and the maximum velocity of the CTB slurry appears at the bottom of the vertical bend at inflection point $\mathrm{D}$ (Figure 7). When the inflection point is encountered, the slurry velocity will surge because of the sudden change in flow direction. The higher the slurry velocity, the greater the impact force on the pipe wall, and the more serious the pipe wall abrasion to be caused. As shown in Figure 8, when the SC of the CTB slurry is between $65 \%$ and $68 \%$, the maximum velocity at $\mathrm{D}$ is at the minimum similar to the wear of the elbow. In addition, in the whole pipeline transportation process, the pipe wall also has friction resistance to the slurry, so that the slurry velocity decreases. 


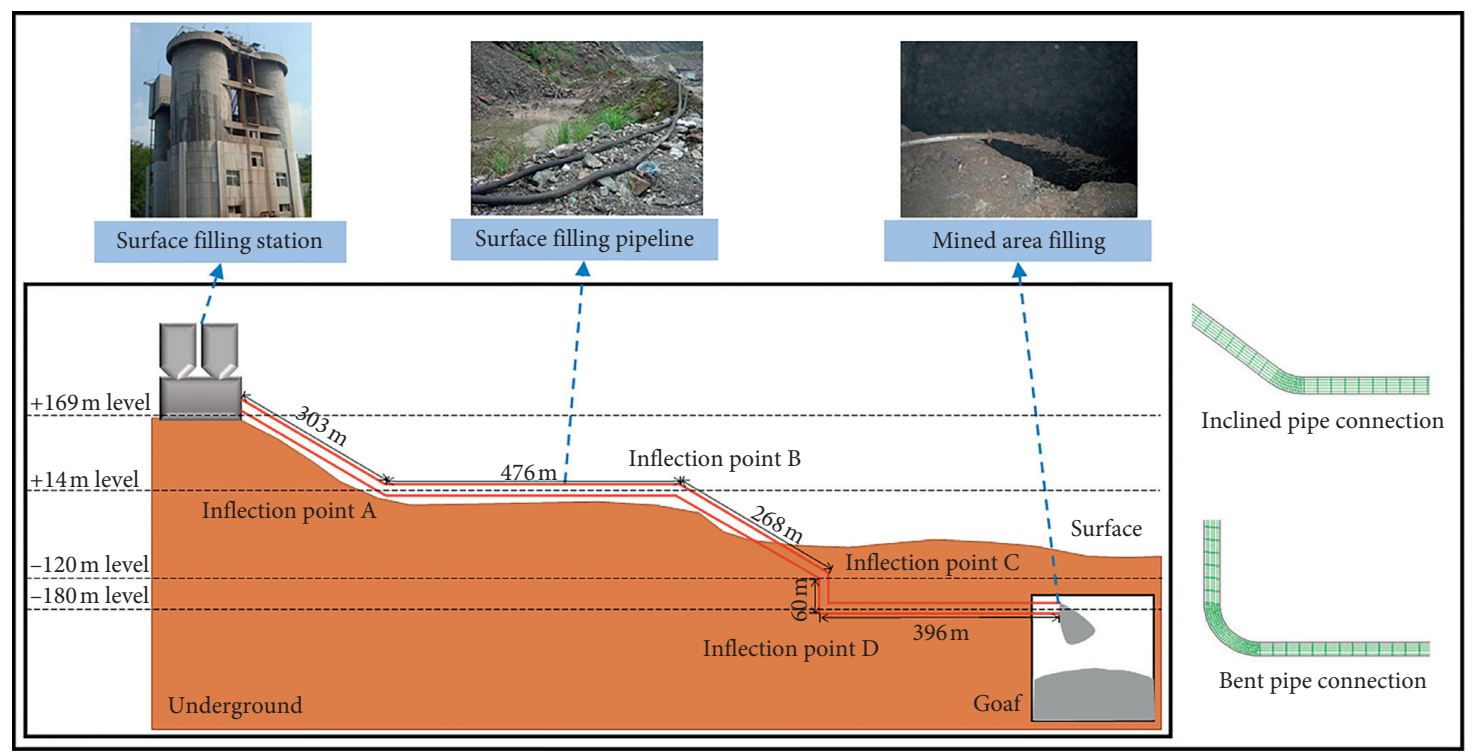

FIgURE 6: Filling pipe model.

TABLE 6: Setting parameters of CTB slurry with different SCs.

\begin{tabular}{|c|c|c|c|c|}
\hline SC (\%) & Density $\left(\mathrm{kg} / \mathrm{m}^{3}\right)$ & Viscosity $(\mathrm{Pa} \cdot \mathrm{s})$ & Flow rate $\left(\mathrm{m}^{3} / \mathrm{h}\right)$ & Inlet velocity $(\mathrm{m} / \mathrm{s})$ \\
\hline \multirow{3}{*}{60} & \multirow{3}{*}{1693} & \multirow{3}{*}{$7.85 \times 10^{-5}$} & 50 & 1.21 \\
\hline & & & 65 & 1.57 \\
\hline & & & 80 & 1.93 \\
\hline \multirow{3}{*}{63} & \multirow{3}{*}{1754} & \multirow{3}{*}{$4.04 \times 10^{-5}$} & 50 & 1.21 \\
\hline & & & 65 & 1.57 \\
\hline & & & 80 & 1.93 \\
\hline \multirow{3}{*}{65} & \multirow{3}{*}{1797} & \multirow{3}{*}{$2.06 \times 10^{-4}$} & 50 & 1.21 \\
\hline & & & 65 & 1.57 \\
\hline & & & 80 & 1.93 \\
\hline \multirow{3}{*}{68} & \multirow{3}{*}{1865} & \multirow{3}{*}{0.03} & 50 & 1.21 \\
\hline & & & 65 & 1.57 \\
\hline & & & 80 & 1.93 \\
\hline \multirow{3}{*}{70} & \multirow{3}{*}{1914} & \multirow{3}{*}{0.22} & 50 & 1.21 \\
\hline & & & 65 & 1.57 \\
\hline & & & 80 & 1.93 \\
\hline
\end{tabular}

3.2.2. Analysis of Pressure Change. Figures 9-13 illustrate the pipeline transportation. The abscissa in the figure represents the length of the pipe section at the exit, and the position from 0 to $0.121 \mathrm{~m}$ is from the top of the pipe to the bottom of the pipe. The dynamic pressure on the cross section of the pipeline gradually decreases from the center line to the pipe wall, whereas the static pressure increases gradually from the center line to the pipe wall. Moreover, the static pressure in the pipeline is much greater than the dynamic pressure. Thus, the pressure on the pipe wall is mainly static pressure. A comparison of the static pressure distribution diagram of the five SCs indicates that when the SC is $60 \%$ and $63 \%$, the static pressure is asymmetrically distributed along the pipe diameter, and the slurry flow is unstable. When the SC exceeds $65 \%$, the static pressure begins to be symmetrically distributed, and the slurry flow state is relatively stable.
3.2.3. Analysis of Pressure Difference Change. As shown in Figure 14, when the SC of the CTB slurry is increased, the pressure difference between the inlet and outlet of the backfilling pipe increases gradually, and the static pressure difference changes prominently. Moreover, when the SC reaches $70 \%$, the static pressure difference suddenly increases sharply. Compared with the static pressure difference, the dynamic pressure difference at the inlet and outlet also increases with the increase in SC, but the increase rate is weak. Therefore, when considering the total pressure difference, the dynamic pressure difference can be ignored and only the static pressure difference can be considered. According to the Bernoulli equation, the resistance loss of the backfilling pipeline increases with the increase in the pressure difference between the inlet and outlet of the backfilling pipeline. When the SC reaches $70 \%$, the pressure difference between the inlet and outlet 


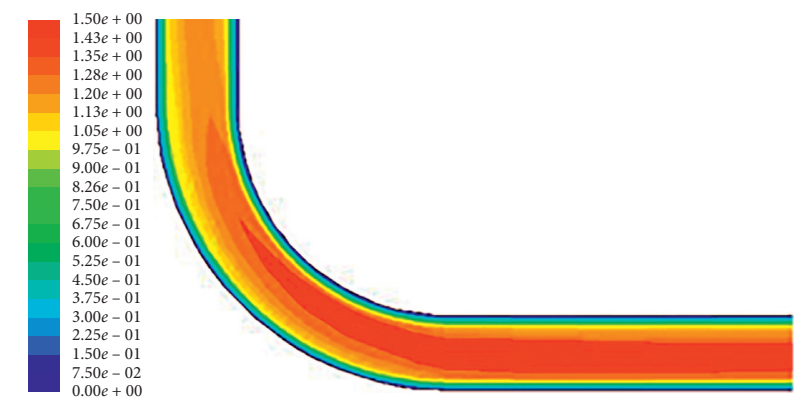

FIGURE 7: Location of maximum velocity, inflection point D.

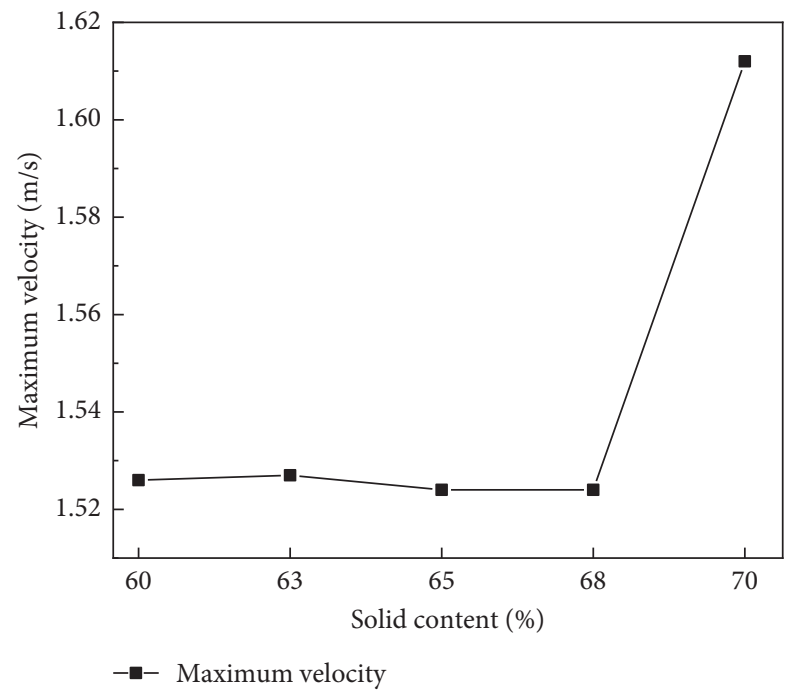

Figure 8: Maximum velocity of slurry with different SC in the pipeline.

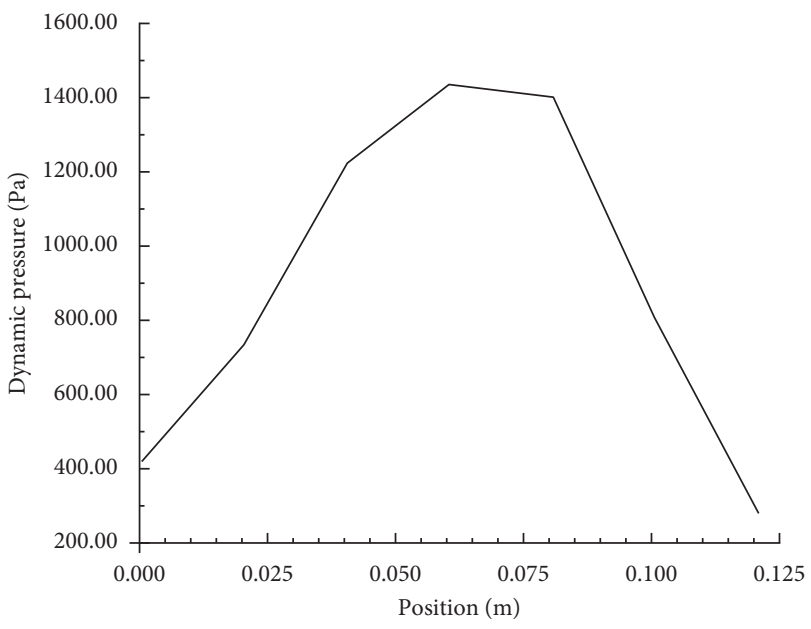

(a)

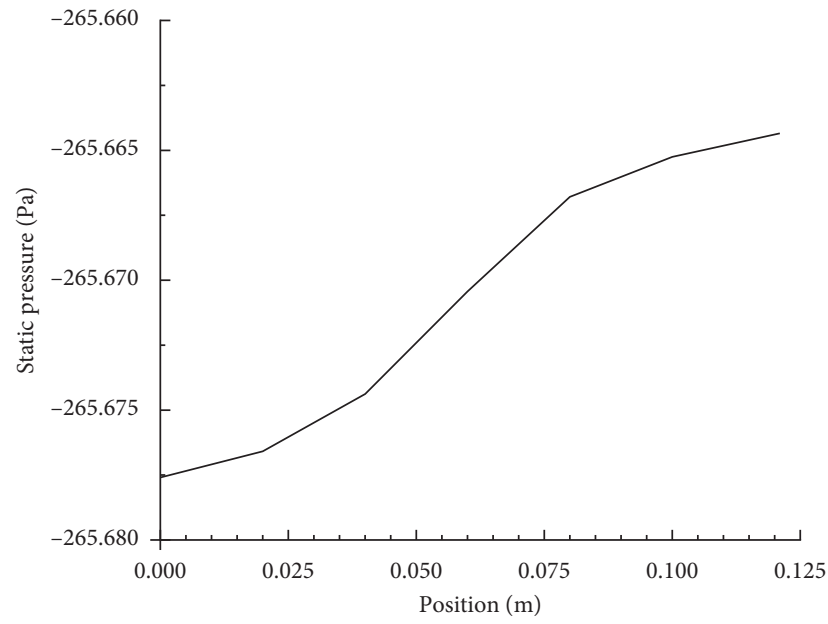

(b)

FIGURE 9: Outlet pressure distribution of slurry with solid content 60\% (Pa): (a) dynamic pressure; (b) static pressure. 


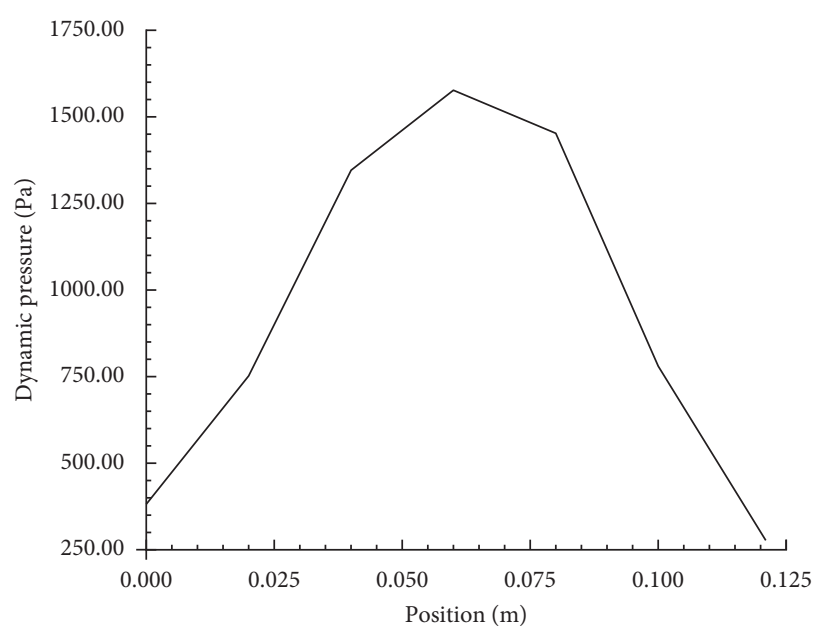

(a)

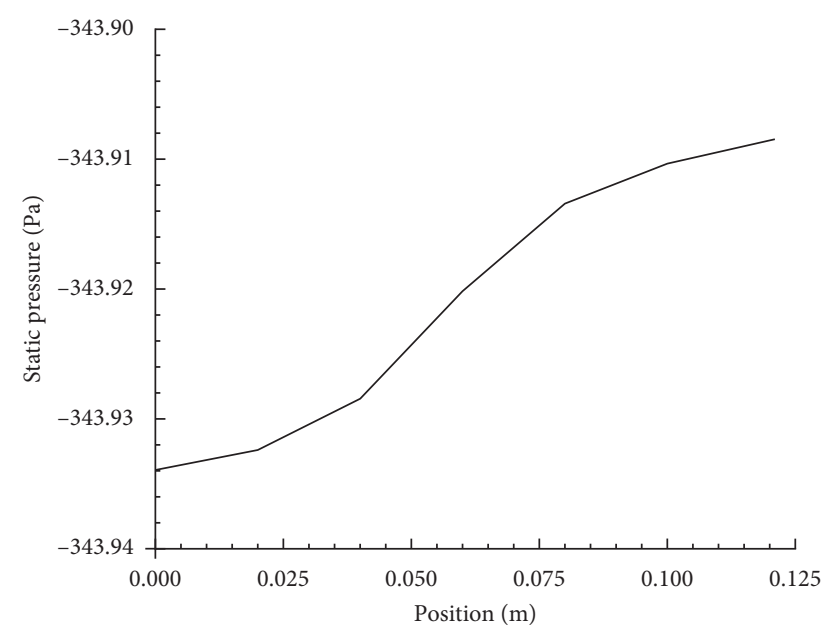

(b)

FIGURe 10: Outlet pressure distribution of slurry with solid content 63\% (Pa): (a) dynamic pressure; (b) static pressure.

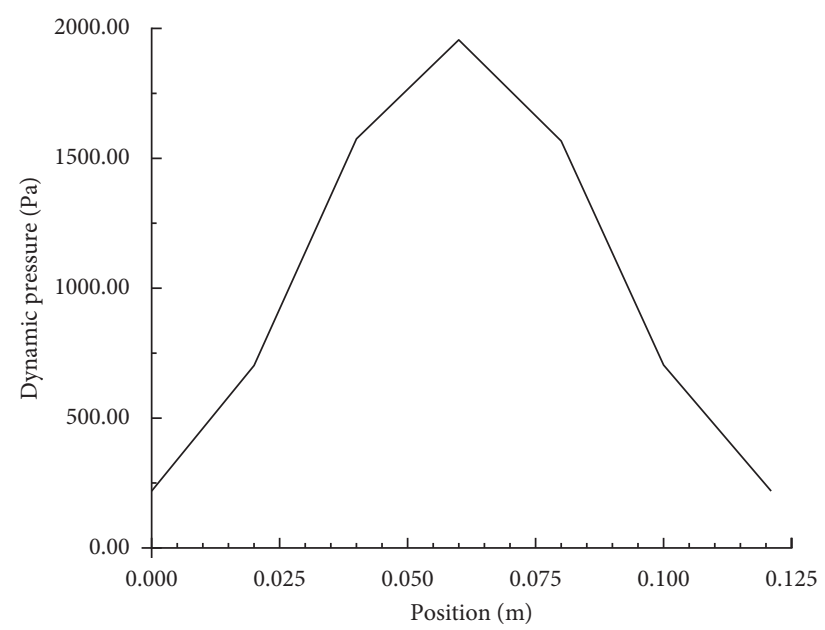

(a)

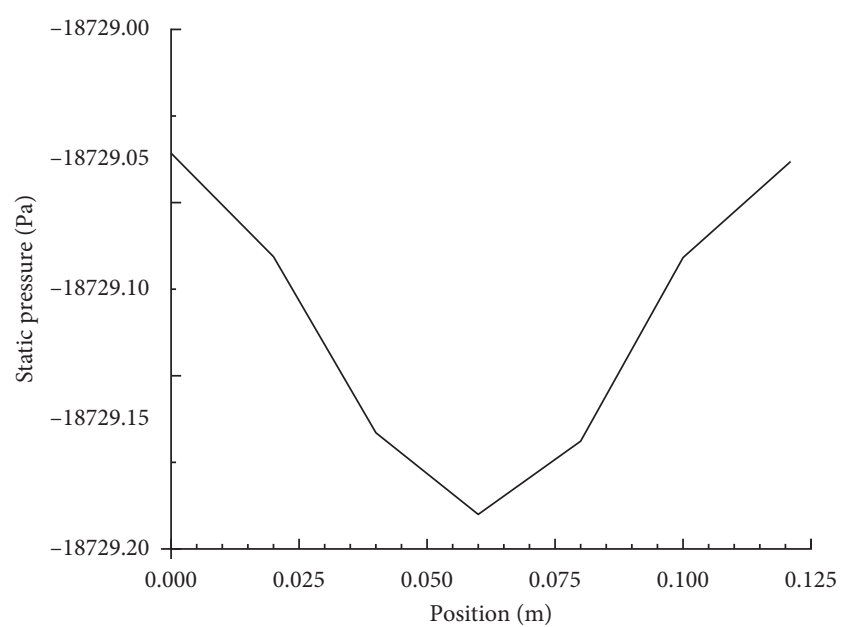

(b)

Figure 11: Outlet pressure distribution of slurry with solid content 65\% (Pa): (a) dynamic pressure; (b) static pressure.

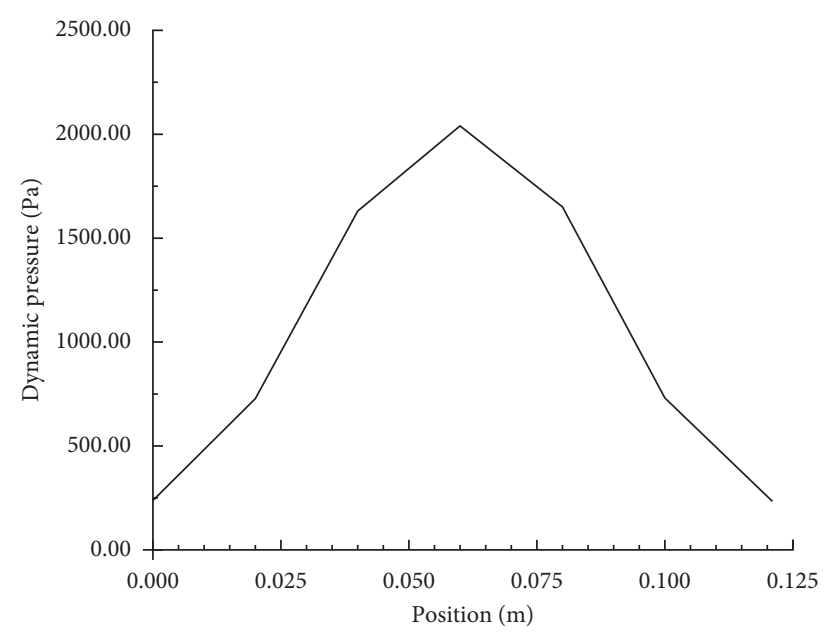

(a)

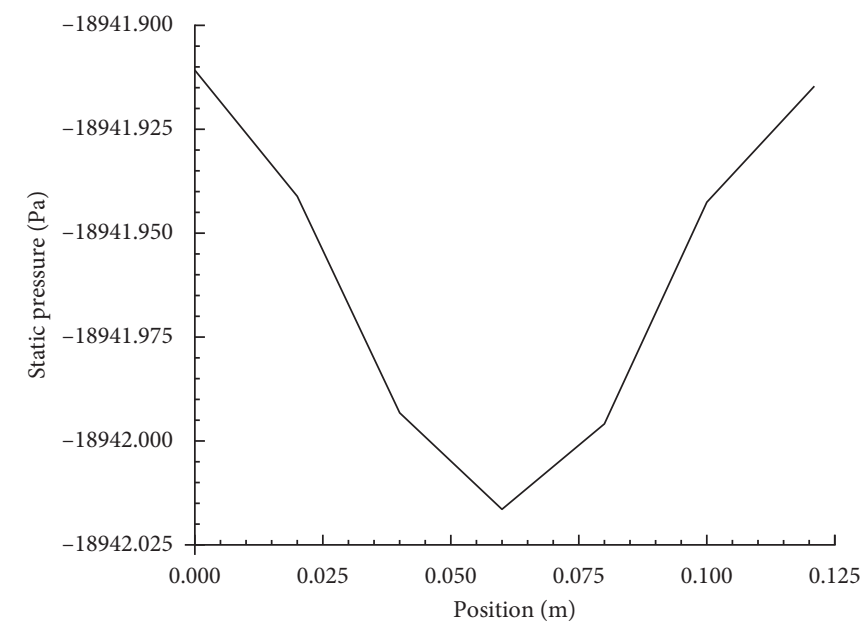

(b)

FIgURE 12: Outlet pressure distribution of slurry with solid content $68 \%(\mathrm{~Pa})$ : (a) dynamic pressure; (b) static pressure. 


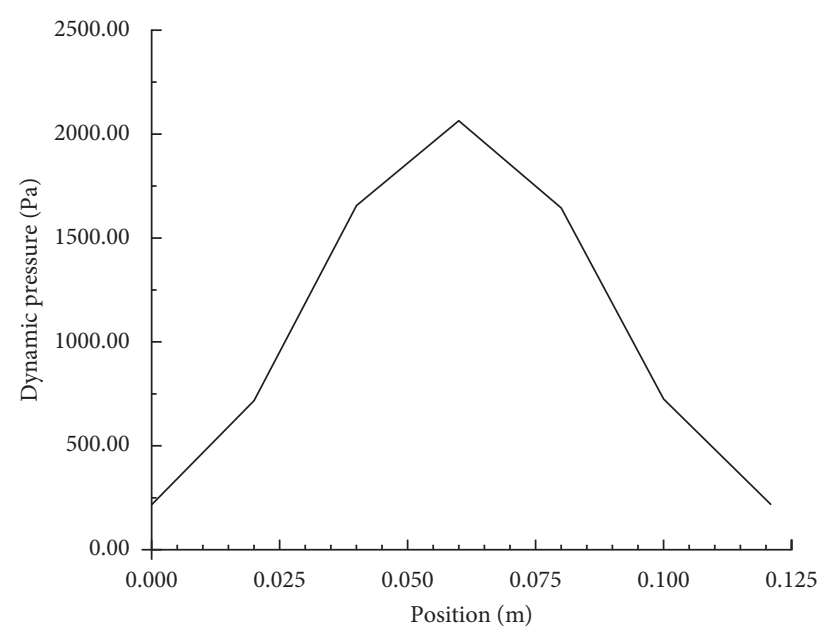

(a)

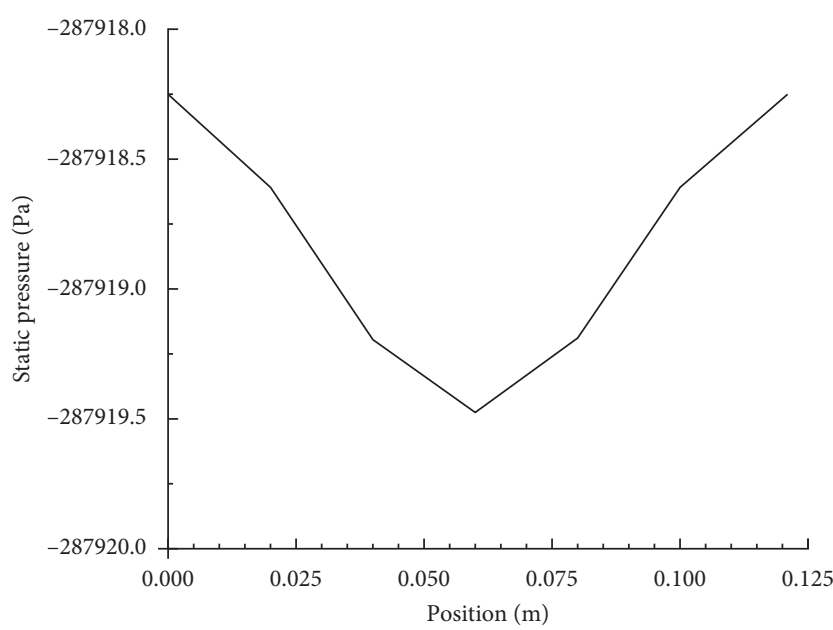

(b)

FIgURE 13: Outlet pressure distribution of slurry with solid content 70\% (Pa): (a) dynamic pressure; (b) static pressure.

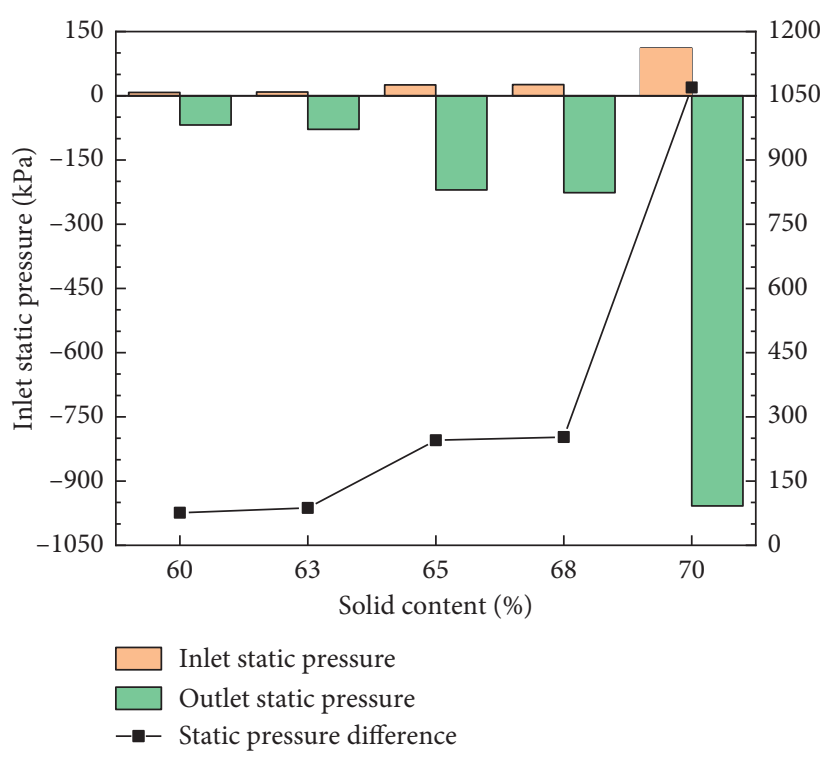

(a)

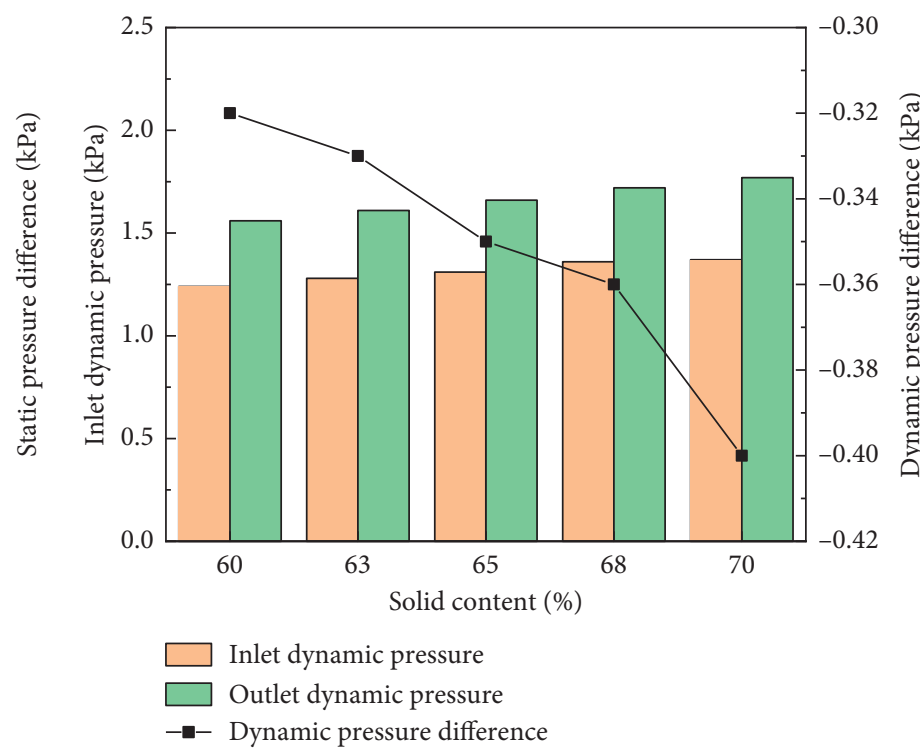

(b)

FIGURE 14: Inlet and outlet pressure of slurry with different SCs: (a) dynamic pressure; (b) static pressure.

increases greatly, which leads to the increase in resistance loss along the pipeline and the risk of pipe plugging.

\subsection{Analysis of the Influence of Flow Rate on Pipeline} Transportation. Take the CTB slurry with SC of $65 \%$ as an example. Then, the velocity and pressure of the pipeline's self-flowing transportation under different flow rates (i.e., different inlet velocities) are analyzed. The three slurries with flow rates of 50,65 , and $80 \mathrm{~m}^{3} / \mathrm{h}$ are selected for simulation. The results are shown in Figures 15 and 16. With the increase in flow rate of the filling slurry, the inlet velocity increases correspondingly, and the maximum velocity in the pipeline also increases. However, the location of the maximum velocity remains at inflection point $\mathrm{D}$. The variation of static pressure is much greater than that of dynamic pressure.
With the increase in flow rate, the pressure difference at the inlet and outlet of the pipeline gradually increases, and the resistance loss of the pipeline also increases. The greater the filling flow rate, the greater the resistance loss.

3.4. Analysis of Wear Law of the Pipeline. Taking the CTB slurry with flow rate of $50 \mathrm{~m}^{3} / \mathrm{s}$ and SC of $70 \%$ as an example, the distribution of velocity and pressure in the filling pipe network is analyzed.

Figure 17 shows the change of flow velocity near the inlet of the model. It can be seen from the figure that the flow velocity near the pipe wall is low and the flow state is stable. The slurry flow velocity in the central part of the pipe is gradually increasing, and the closer to the center, the greater the flow velocity. 


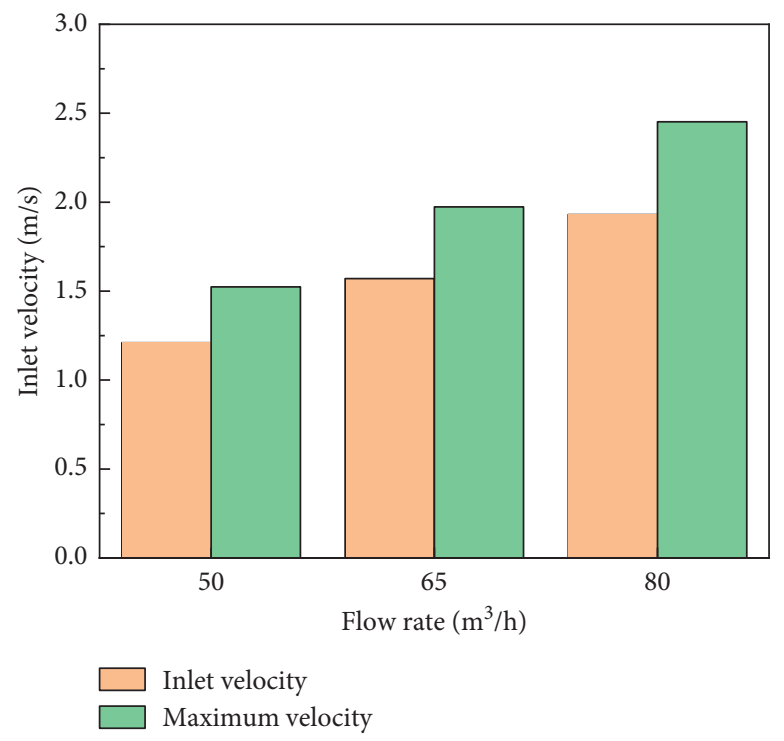

FIGURE 15: Maximum velocity of slurry with different flow rates in the pipeline.

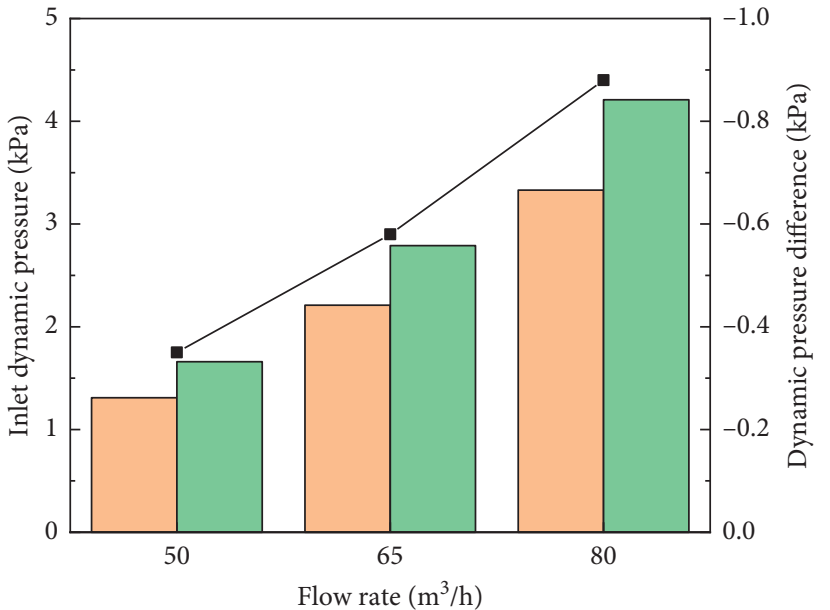

Inlet dynamic pressure

Outlet dynamic pressure

Dynamic pressure difference

(a)

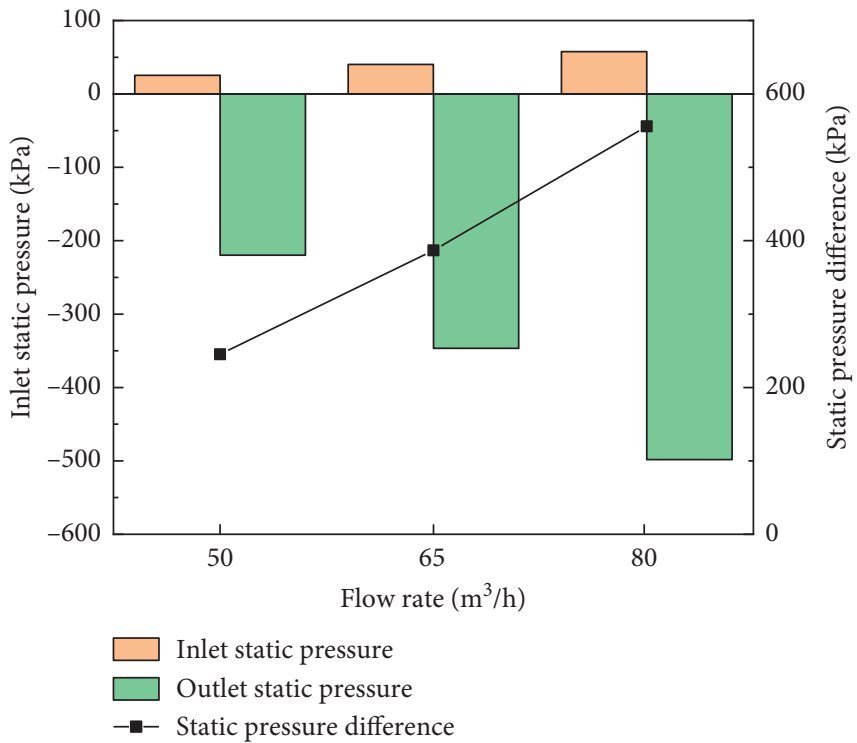

(b)

FIgURE 16: Inlet and outlet pressure of slurry with different flow rates: (a) dynamic pressure; (b) static pressure.

Figure 18 shows the velocity distribution near the four inflection points in the pipeline model. The slurry velocity changes abruptly at the elbow in Figure 18(c), and the velocity increases from the inlet near the elbow to the outlet of the elbow. The maximum velocity occurs from a small section before the outlet of the elbow to the outlet of the elbow.

From the velocity distribution of four inflection points $A, B, C$, and D, it can be seen that the velocity of slurry will surge at every bend, especially at inflection points $C$ and $D$, which have higher velocity on the inner wall of the transition to the vertical pipe section. It can be seen that the impact of the filling slurry on the inclined pipe and elbow is very strong, especially on the inside of the elbow near the vertical pipe section.
Figure 19 shows the pressure distribution at the four inflection points; it can be seen that the results of pressure distribution are completely consistent with that of velocity distribution. The larger part of pressure appears in the inside of inclined pipe and elbow. The most prominent part of pressure is the transition part from elbow to vertical pipe, and the pressure of the transition part of adjacent horizontal pipe cannot be ignored. The pressure at the bottom wall of horizontal pipe is higher than that at the upper wall. Therefore, it can be inferred that the most seriously worn parts in the filling pipe network are inflection points $\mathrm{A}, \mathrm{B}, \mathrm{C}$, and $D$, the transition parts of the adjacent vertical and horizontal pipe sections, and the bottom wall of the horizontal pipe section. 


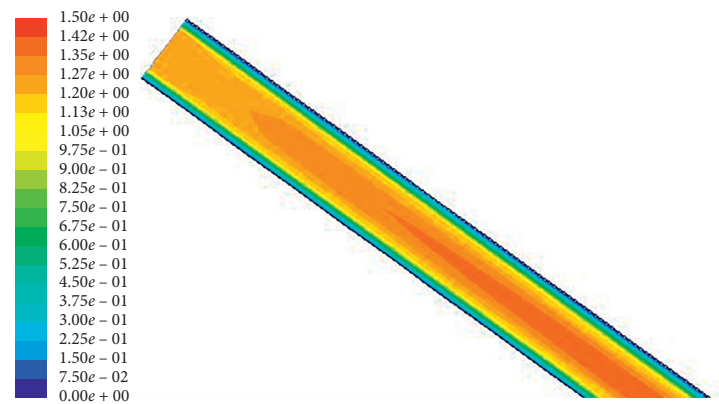

Figure 17: The velocity distribution of $70 \%$ slurry near the inlet.

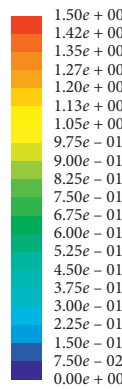

$1.50 e+00$
$1.42 e+00$
$1.35 e+00$
$1.27 e+00$
$1.20 e+00$
$1.13 e+00$
$1.05 e+00$
$9.75 e-01$
$9.00 e-01$
$8.25 e-01$
$7.50 e-01$
$6.75 e-01$
$6.00 e-01$
$5.25 e-01$
$4.50 e-01$
$3.75 e-01$
$3.00 e-01$
$2.25 e-01$
$1.50 e-01$
$7.50 e-02$
$0.00 e+00$

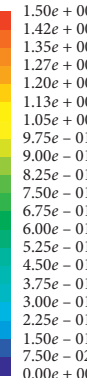

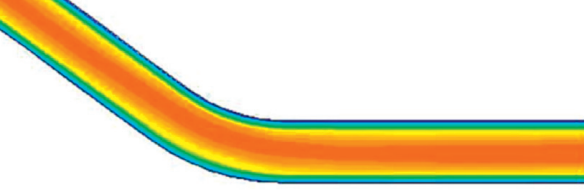

(a)

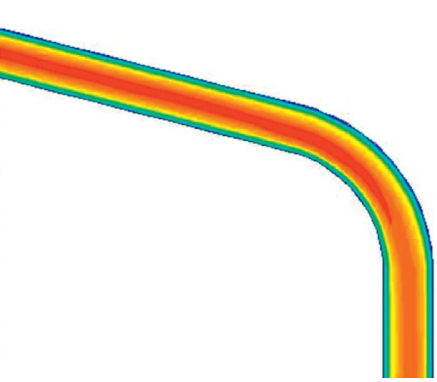

(c)
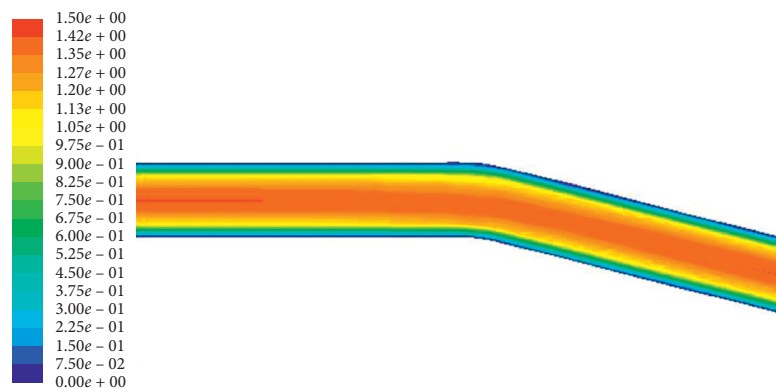

(b)
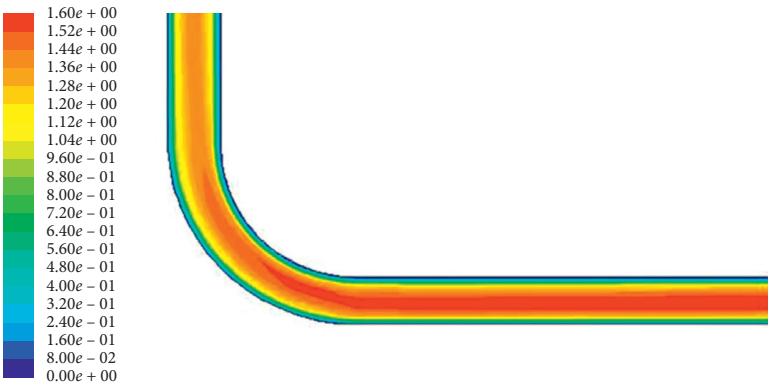

(d)

Figure 18: The velocity distribution: (a) inflection point A; (b) inflection point B; (c) inflection point C; (d) inflection point D.

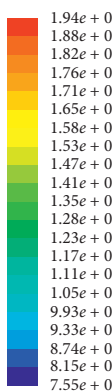

$1.76 e+03$

$65 e+03$

$1.58 e+03$

$1.47 e+03$

$.35 e+03$

$.28 e+03$

(17e+03

$1 e+03$

$93 e+02$

(1)

$8.15 e+02$

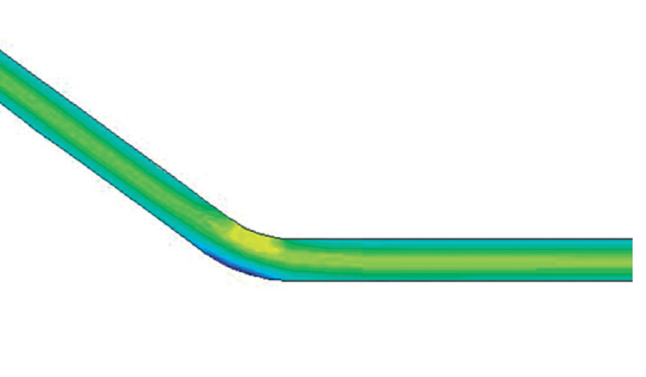

(a)

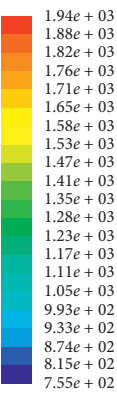

$1.82 e+03$

$1.76 e+03$
$1.71 e+03$

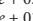

$28 e+03$

$.23 e+03$
$.17 e+03$
$1.11 e+03$

. $33 e+02$

$.15 e+02$

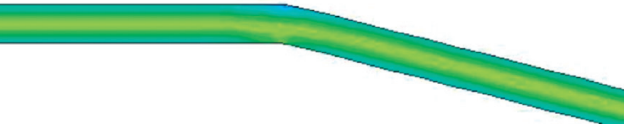

Figure 19: Continued.

(b) 


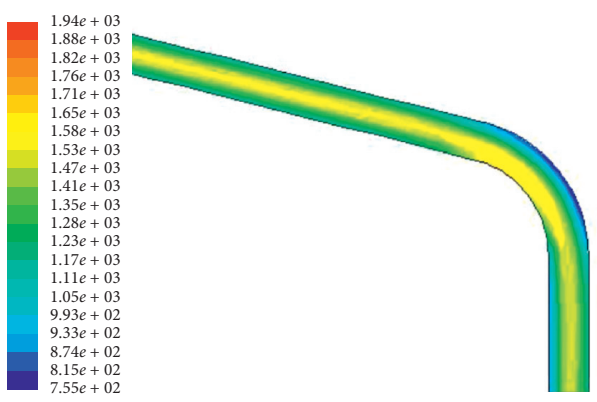

(c)
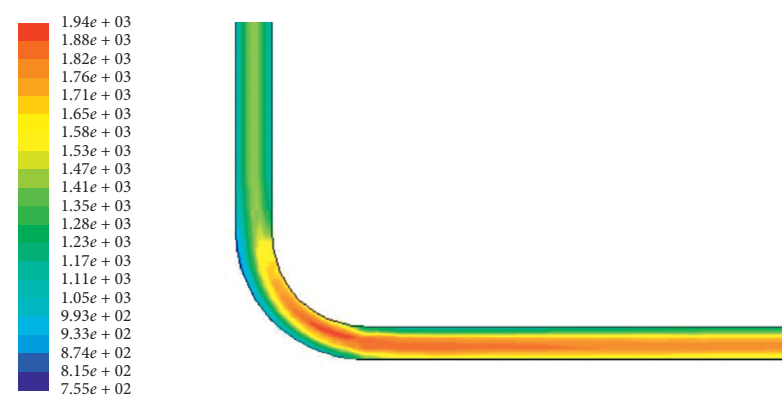

(d)

Figure 19: The pressure distribution: (a) inflection point A; (b) inflection point B; (c) inflection point C; (d) inflection point D.
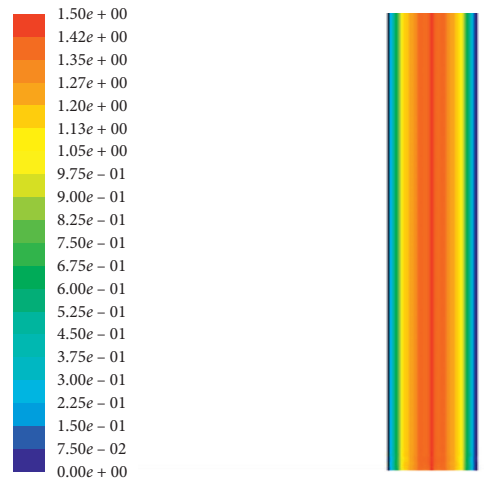

FIGURE 20: The velocity distribution of $70 \%$ slurry in vertical pipe section.

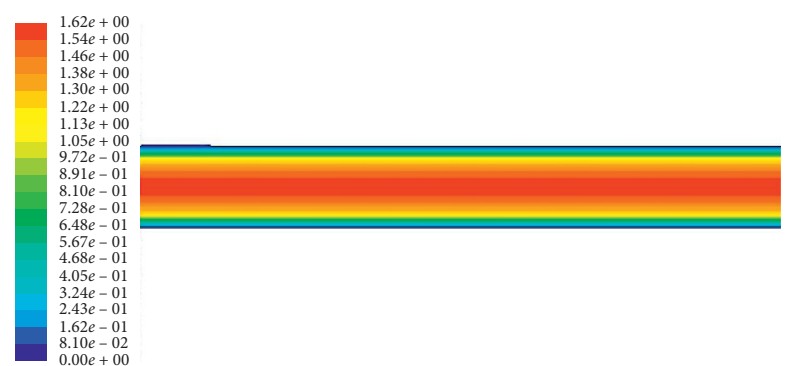

Figure 21: The velocity distribution of $70 \%$ slurry in horizontal pipe.

Figures 20 and 21 show the velocity distribution of slurry in vertical and horizontal sections, respectively. According to the figure, the velocity of slurry in the stable pipe section is basically stable, and the maximum velocity appears near the center line of the pipeline, and the flow velocity decreases from the center of the pipe to the pipe wall, and the flow velocity at the pipe wall is the lowest. It can be seen from Figure 20 that the slurry fluidity at the bottom of horizontal pipe is obviously higher than that of upper part within a distance of the horizontal pipe just reaching the horizontal pipe. Therefore, it can be seen that the abrasion of the pipe wall at the bottom of the horizontal pipe section is more serious than that of the upper part.

\section{Conclusion}

The rheological parameters and transport characteristics of fresh CTB slurry were studied by laboratory test and numerical simulation. The main conclusions are as follows:

(1) When the SC of fresh CTB slurry varies among the range of $60 \%-65 \%$, the change rule of the fitting curve between dynamic yield stress, viscosity, and SC conforms to the H-B model. With the increase in SC, the fitting curve gradually transits from nonlinear to linear. Even more, when the SC reaches $70 \%$ and upon, the fitting curve changes from the H-B model to the Bingham model. 
(2) With the increase in SC of the CTB slurry, the dynamic yield stress and viscosity increase exponentially, and the viscosity increases significantly when the SC reaches $70 \%$.

(3) When the SC is between $60 \%$ and $63 \%$, the slurry flow is unstable, and the pressure distribution in the pipe is uneven. When the SC is between $65 \%$ and $68 \%$, the slurry flow state is relatively stable, and the pressure distribution is symmetrical along the pipe diameter. When the SC reaches $70 \%$, the pressure difference suddenly increases, and the resistance loss in the pipeline increases greatly.

(4) In order to avoid pipe plugging accident, the filling slurry concentration should be less than $70 \%$. According to the analysis results of flow velocity and pressure, it is best to control the slurry concentration between $65 \%$ and $68 \%$ in the Daye iron mine.

(5) With the increase in flow rate of the CTB slurry, the maximum velocity in the pipeline increases, and the static pressure difference between the inlet and outlet of the pipeline increases significantly, which leads to the increase in resistance loss of the pipeline. Therefore, smaller inlet velocity can be controlled to reduce the resistance loss of the pipeline.

(6) Aiming at the inflection points A, B, C, and D, the transition part of the adjacent vertical pipe section and horizontal pipe section, and the bottom wall of the horizontal pipe section, which is the most serious wear problem of the filling pipe network in Daye iron mine, wear-resistant pipe material can be used to strengthen the inflection point, and the horizontal pipe can be turned over regularly.

\section{Data Availability}

The data used to support the findings of this study are included within the article.

\section{Conflicts of Interest}

The authors declare no conflicts of interest.

\section{Acknowledgments}

This research was funded by the National Natural Science Foundation of China Youth Fund (52004019).

\section{References}

[1] W. Qi-Ming, X. Bi-Gen, T. Shao-Hui, C. Xie, and A.-H. Bao, "The actual state of mined-out areas in metallic and nonmetallic mines and the countermeasures for the treatment of the mined-out areas in China," Mining Research and Development, vol. 29, no. 4, pp. 63-68, 2009.

[2] B.-W. Wang, T.-Y. Xiong, G. Lijing, C. Yue-peng, X.-Y. Cui, and W. Ding, "Effects of tailings gradation on rheological properties of filling slurry," Advances in Civil Engineering, vol. 2019, pp. 1-11, 2019.
[3] Y.-X. Liu, L. Zhi-Xiang, L. Keming, S.-J. Deng, and L.-J. Dong, "A Cleaner Mining Method for Waste Tailings as Paste Materials to GoChaiafs," Geofluids, vol. 2020, pp. 1-16, 2020.

[4] W. Jiang-Yu, J. Hong-Wen, Y. Qian, Y. Liyuan, B. Meng, and L. Shun-Cai, "Strength prediction model considering material, ultrasonic and stress of cemented waste rock backfill for recycling gangue," Journal of Cleaner Production, vol. 276, Article ID 123189, 2020.

[5] D. Ma, H. Duan, J. Liu, X. Li, and Z. Zhou, "The role of gangue on the mitigation of mining-induced hazards and environmental pollution: an experimental investigation," The Science of the Total Environment, vol. 664, pp. 436-448, 2019.

[6] X. Chang-nian and X.-S. Sun, "Application and developing trend of filled stopes method and filling technology," China Mine Engineering, vol. 43, no. 1, pp. 61-64, 2014.

[7] A.-M. Zhou, Mine Waste Cementation and Filling, Metallurgical Industry Press, Beijing, China, 2010.

[8] X.-M. Wang, J.-W. Zhao, J.-H. Xue, and G.-F. Yu, "Features of pipe transportation of paste-like backfilling in deep mine," Journal of Central South University, vol. 18, no. 5, pp. 14131417, 2011.

[9] M. Aubertin and B. Bussiere, "Meeting environmental challenges for mine waste management," Geotechnical News, vol. 19, no. 3, pp. 21-26, 2001.

[10] Y.-G. Zhai, A.-X. Wu, H.-J. Wang, C. Qin-Rui, X. Yun-Tao, and $\mathrm{S}$. Zhen-Yu, "Threshold mass fraction of unclassifiedtailings paste for backfill mining," Chinese Journal of Engineering, vol. 37, no. 7, pp. 795-799, 2014.

[11] D. Hewitt, S. Allard, and P. Radziszewski, "Pipe lining abrasion testing for paste backfill operations," Minerals Engineering, vol. 22, no. 12, pp. 1088-1090, 2009.

[12] S. Cao, G.-L. Xue, E. Yilmaz, and Z.-Y. Yin, “Assessment of rheological and sedimentation characteristics of fresh cemented tailings backfill slurry," International Journal of Mining, Reclamation and Environment, vol. 35, no. 5, pp. 319-335, 2020.

[13] S. Cao, E. Yilmaz, and W. Song, "Evaluation of viscosity, strength and microstructural properties of cemented tailings backfill," Minerals, vol. 8, no. 8, p. 352, 2018.

[14] C. Yang, L.-J. Guo, L. Zhang, L.-M. Hu, and X. Wen-Yuan, "Study of the rheological characteristics of copper tailings and calculation of resistance in pipeline transportation," Chinese Journal of Engineering, vol. 39, no. 5, pp. 663-668, 2017.

[15] S.-J. Cai, G. Huang, D. Wu, and Y.-D. Zhang, "Experimental and model study on rheological properties of tailings backfill," Journal of Northeastern University, vol. 36, no. 6, pp. 882-886, 2015.

[16] X.-M. Wang, W.-G. Xiao, X.-W. Wang, and X. Zhi-Zeng, "Study on rheological properties of full tailing paste filling slurry of Jinchuan mine," Mining and Metallurgical Engineering, vol. 22, no. 3, pp. 13-16, 2002.

[17] Y.-P. Kou, Z.-J. Qi, Z.-P. Song, J.-F. Du, and J.-G. Yang, "Experimental study on rheological properties of high-concentration filling slurry with full tailings," Mining Research and Development, vol. 38, no. 12, pp. 32-35, 2018.

[18] X. Wang, X.-Y. Zhao, Q. Yuan-Yuan, W.-W. Hu, J. Chen, and $\mathrm{M}$. Wu, "Experimental research on particle characteristics and rheological properties of high concentration red mud," Metal Mine, vol. 379, no. 1, pp. 107-109, 2008.

[19] F. Wu, X.-B. Yang, Y. Zhi-qiang, and Q. Gao, “Anti-segregation property and its mathematical model of high concentration filling slurry with coarse aggregate," Journal of Central South University, vol. 51, no. 5, pp. 1309-1316, 2020. 
[20] L. Ming-Zhi, Y.-P. He, Y.-D. Liu, and C. Huang, "Analysis of transport properties with varying parameters of slurry in horizontal pipeline using ANSYS fluent," Particulate Science and Technology, vol. 38, no. 6, pp. 726-739, 2019.

[21] Q.-L. Zhang, L. Qi, J.-W. Zhao, and J.-G. Liu, "Pipeline transportation characteristics of filling paste-like slurry pipeline in deep mine," Chinese Journal of Nonferrous Metals, vol. 25, no. 11, pp. 3190-3195, 2015.

[22] J.-H. Chen, C. Qiao-xi, Q.-L. Zhang, and H. Li, "Computer simulation of filling slurry pipeline transportation using Fluent," Science and Technology Review, vol. 33, no. 9, pp. 64-68, 2015.

[23] X.-X. Zhang and D.-P. Qiao, "Simulation and experiment of pipeline transportation of high density filling slurry with coarse aggregates," Chinese Journal of Nonferrous Metals, vol. 25, no. 1, pp. 258-266, 2015.

[24] D.-Q. Deng, L. Wang, Y. Zhou, and Y.-X. Zhang, "Experimental analysis on the transportation simulation of filling slurry in L-shape pipeline," Journal of Guangxi University: Natural Sciences Education, vol. 37, no. 4, pp. 837-843, 2012.

[25] D.-Q. Deng, Y.-J. Zhu, F.-Z. Wang, L. Wang, and W.-J. Yu, "Transportation numerical simulation of filling slurry in long distance pipeline," Journal of Anhui University (Natural Science Edition), vol. 36, no. 6, pp. 36-43, 2012.

[26] S.-Y. Xiao, L. Zhi-Xiang, Y.-J. Jiang, L. Cheng, S. Chang-Ning, and L.-J. Su, "Remote pipeline pumping transportation of cemented tailings backfill slurry," Archives of Mining Sciences, vol. 63, no. 3, pp. 647-663, 2018.

[27] L. Zhang, D.-P. Qiao, W.-H. Cheng, G.-L. Zhang, and H. Guoquan, "Analysis on gradation and intensity of coarse aggregate on JNMC," Mining and Metallurgical, vol. 21, no. 3, pp. 12-15, 2012.

[28] Y.-N. Tang, J.-X. Fu, W.-D. Song, and Y.-F. Zhang, "Mechanical properties and crack evolution of interbedded cemented tailings backfill," Chinese Journal of Engineering, vol. 42, no. 10, pp. 1286-1298, 2020.

[29] Y.-Y. Tan, K. Zhang, X. Yu, W.-D. Song, J. Wang, and H. Cheng-Long, "The mechanical and microstructural properties of composite structures made of a cement-tailing backfill and rock core," Minerals, vol. 10, no. 2, p. 159, 2020.

[30] Y. Gen-Bo, P. Yang, Z. Chen, and M. Rui-Ying, "Study on pipeline self-flowing transportation of cemented tailing fill slurry based on FLUENT software," Advanced Materials Research, vol. 734-737, pp. 833-837, 2013. 